\title{
Incidence of Antenatally Detected Congenital Anomalies in A Tertiary Care Hospital in A Rural Setting-A Prospective Observational Study
}

\author{
Gokul Krishnan $\mathbf{R}^{1 *}$, Nirmala $\mathrm{P}^{2}$ and Chandrasekhar $\mathbf{G}^{3}$ \\ ${ }^{1}$ Division of Neonatology, Assistant Professor of Paediatrics, Narayana Medical College, India \\ ${ }^{2}$ Assistant professor of Obstetrics \& Gynaecology, Narayana Medical College, India \\ ${ }^{3}$ Assistant professor of Paediatrics, Narayana Medical College, India \\ *Corresponding author: Dr R Gokul Krishnan, Division of Neonatology, Assistant Professor of Paediatrics, Narayana Medical College, \\ Chinthareddypalem, Nellore, Andhra Pradesh, India
}

\begin{abstract}
Background: Congenital anomalies are an important cause of neonatal and infant mortality, contribute upto $11 \%$ of neonatal deaths globally. With increasing use of routine prenatal ultrasound, early identification of these anomalies is possible in antenatal period and thereby adequate counselling could be done by the Neonatologists. The present study was done to know the incidence, pattern of congenital anomalies and various presentations, which may help for antenatal parents counselling and subsequent management after delivery.

Aim and Objectives: The aim of our study was to analyze the antenatal incidence of major congenital anomalies in our hospital.

Methods: This is a cross-sectional study done in the Neonatal division, Department of Pediatrics at Narayana Medical College hospital, Nellore, India between January 2018 to December 2019 (Two years). All antenatal mothers attending the outpatient department of Obstetrics \& Gynecology were included in the study and subjected to TIFFA Scans. All antenatal mothers who gave consent for the study were recruited. The study was started after obtaining the ethical committee approval from our institute. Ultrasound screening of 7588 fetuses were performed and Pregnancies with fetal congenital anomalies were studied and necessary antenatal counselling was given by the Neonatologist.
\end{abstract}

Results: A total of 7588 antenatal mothers were screened for congenital anomalies in the 2nd and 3rd trimester by ultrasonography (USG). Out of these 265 numbers of congenital anomalies were detected. Incidence of fetal congenital anomalies was $3.4 \%$. Among the fetal congenital anomalies, renal anomalies were the most common.

Conclusion: Antenatal ultrasound is a non-invasive, sensitive, and cost-effective imaging technique which gives good results in experienced hands. Prenatal diagnosis of congenital anomalies provides information for proper decisions during pregnancy, fetal intervention if necessary, parental counselling and appropriate perinatal treatment, thereby improving perinatal outcomes.

Keywords: Antenatal congenital anomalies; TIFFA; Renal anomalies; Neonatologist

\section{Introduction}

Congenital anomalies are major cause of stillbirths and neonatal mortality in India, also pose a health care burden to the community. World Health Organization (WHO) defined congenital anomalies as structural or functional anomalies, including metabolic disorders which are present at the time of birth [1,2]. Congenital anomalies are a major universal problem, as every year an estimated 7.9 million children are born with a serious birth defects [3]. Though the reported incidence of congenital anomalies at birth is $2-3 \%$, actual incidence is higher due to high number of abortions that remain unknown. Though folic acid and zinc deficiency has been proved to cause Neural tube defects, the incidence has significantly decreased due to peri-conceptional folic acid intake as implemented 
by National health mission guidelines [4]. Maternal anemia, Diabetes mellitus, exposure to drugs and radiation are various other risk factors attributed for causing congenital anomalies. Antenatal congenital anomalies contribute to foetal loss, still births, preterm births, neonatal mortality, and childhood morbidity with significant repercussion on the mothers and their families $[5,6]$. Data on congenital anomalies from developing countries like India are limited and the magnitude, severity of various congenital anomalies vary with various geographical locations. Hence, we intended to study the same in our institute.

\section{Methods}

This was a prospective observational non-interventional study done between January 2018 to December 2019(2 years) in the Neonatal division of department of paediatrics in collaboration with Obstetrics and Radiology departments at Narayana medical college and Hospital. All the antenatal ultrasonograms were performed by Radiologist trained in fetal medicine using" GE USG machine, Model: Voluson T-8, Volume probe (4-d)". All the antenatal mothers attending the Obstetrics out-patient department and gave consent for the study were recruited, subjected to 2nd \& 3rd trimester anomaly scans. The study was conducted after obtaining the ethical committee approval from our institute. Maternal parameters like age, parity, consanguinity, gestational age, diabetes mellitus, PIH, exposure to drugs and radiation were recorded. The diagnosed anomalies were recorded in the Performa. The data was collected and processed using Microsoft Excel and descriptive statistical analysis was done.

\section{Inclusion criteria}

a) All Antenatal mothers attending the Obstetrics and Gynaecology out-patient department.

\section{Exclusion criteria}

a) Antenatal mothers with multiple gestation.

b) Antenatal mothers with refusal of consent.

\section{Results}

\section{Incidence of congenital malformations}

Out of total 7588 singleton pregnancies screened, 265 women were diagnosed to have congenital anomalies. Majority, i.e. 141 out of $265(53.2 \%)$ patients were multigravidae. Incidence of congenital anomalies were higher among maternal age group of $>35$ years (34.7\%). About 155 anomaly fetus (58.5\%) were seen in women above 30 years of age. Antenatal mothers between 26-30 years had 35(13.2\%) anomalous babies and between 22-25 years had $26(9.8 \%)$ babies with anomalies. Around 49(18.5\%) congenital anomalies were noted in teenage pregnant mothers of 18-21 years. About 138 of 265 antenatal congenital anomalies (52\%) were seen in consanguineous marriages. The maternal age, parity, and consanguinity wise distribution of antenatal congenital anomalies in the study group is depicted in Table 1.

Table 1: Demographic Profile of The Study Population.

\begin{tabular}{|c|c|c|c|c|}
\hline Parameters & \multicolumn{2}{|c|}{ No of Antenatal Mothers $(\mathrm{N}=7588), \mathrm{n}(\%)$} & $\begin{array}{l}\text { No of Congenital } \\
\text { Anomalies }(\mathrm{N}=265), \mathrm{n}(\%)\end{array}$ & Percentage $(\%)$ \\
\hline \multirow{5}{*}{ Maternal age (in years) } & $18-21$ & $1874(24.7)$ & $49(18.5)$ & 2.6 \\
\hline & $22-25$ & $2293(30.2)$ & $26(9.8)$ & 1.2 \\
\hline & $26-30$ & $1465(19.3)$ & $35(13.2)$ & 2.4 \\
\hline & $31-35$ & $1095(14.4)$ & $63(23.8)$ & 5.8 \\
\hline & $>35$ & $861(11.4)$ & $92(34.7)$ & 10.6 \\
\hline \multirow{2}{*}{ Consanguinity } & Consanguineous & $1827(24)$ & $138(52)$ & 7.55 \\
\hline & Non-Consanguineous & $5761(76)$ & $127(48)$ & 2.20 \\
\hline \multirow{2}{*}{ Parity } & Primi & $3491(46)$ & $124(46.8)$ & 3.55 \\
\hline & Multipara & $4097(54)$ & $141(53.2)$ & 3.44 \\
\hline \multicolumn{5}{|c|}{ Maternal Risk Factors } \\
\hline H/O.GDM & \multicolumn{2}{|c|}{$592(7.8)$} & $124(46.8)$ & 21 \\
\hline H/O.PIH & \multicolumn{2}{|c|}{$461(6.1)$} & $53(20)$ & 11.5 \\
\hline H/O.EPILEPSY & \multicolumn{2}{|c|}{$109(1.4)$} & $4(1.5)$ & 3.7 \\
\hline H/O.UTI & \multicolumn{2}{|c|}{$398(5.2)$} & $8(3)$ & 2.1 \\
\hline H/O. Tobacco/Smoking & \multicolumn{2}{|c|}{$31(0.4)$} & $3(1.2)$ & 9.6 \\
\hline H/O. Radiation exposure & \multicolumn{2}{|c|}{$6(0.08)$} & $2(0.8)$ & 33.3 \\
\hline ANEMIA $(\mathrm{Hb}<10)$ & \multicolumn{2}{|c|}{$1028(13.5)$} & $22(8.3)$ & 2.2 \\
\hline USG:-AFI > 20 & \multicolumn{2}{|c|}{$313(4.1)$} & $19(7.2)$ & 6.2 \\
\hline Lack of Iron \& Folic Acid Intake & \multicolumn{2}{|c|}{$289(3.8)$} & $30(11.2)$ & 10.4 \\
\hline
\end{tabular}


Incidence of maternal risk factors associated with congenital anomalies

Maternal risk factors like diabetes mellitus was found to be associated with $46.8 \%$ of anomalous foetus (Table 1). 53 of 461 foetus (20\%) were found to have anomaly in mothers with pregnancy induced hypertension. 30 of 289(11.2\%) anomalous foetus were because of absent or inadequate intake of Iron \& folic acid tablets. Similarly, congenital anomalies associated with anemic mothers were 22(8.3\%), amniotic fluid index(AFI) $>20$ were

Table 2: Gestational Age Wise Incidence of Congenital Anomalies in Antenatal Mothers.

\begin{tabular}{|c|c|c|c|}
\hline Gestational age (in weeks) & $\begin{array}{c}\text { Total Number of Antenatal } \\
\text { Mothers (N=7588) (n=\%) }\end{array}$ & $\begin{array}{c}\text { Congenital Anomalies Congenital } \\
\text { Anomalies }\end{array}$ & Percentage (\%) \\
\hline $16-20$ & $2126(28)$ & $57(21.5)$ & 2.7 \\
\hline $21-25$ & $3369(44.4)$ & $96(36.3)$ & 2.9 \\
\hline $26-30$ & $1571(20.7)$ & $89(33.6)$ & 5.6 \\
\hline$>30$ & $522(6.9)$ & $23(8.6)$ & 4.4 \\
\hline
\end{tabular}

System wise incidence of congenital anomalies in antenatal mothers

In the present study, anomalies involving the renal system were 83(31.4\%), cardiovascular system was 66(24.9\%), musculoskeletal
$19(7.2 \%)$, maternal urinary tract infections(UTI) were $8(3 \%)$ and smoking or tobacco intake were $3(1.2 \%)$ (Table 1 ).

\section{Gestational age wise incidence of congenital anomalies in antenatal mothers}

57 of 265 cases $(21.5 \%)$ of antenatal congenital anomalies were diagnosed between 16-20 weeks gestational age. Congenital anomalies in gestational age of 21-25 weeks was 96 cases (36.5\%), 26-30 weeks was $89(33.6 \%)$ and $>30$ weeks was $23(8.6 \%$ ) (Table 2).

Table 3: System wise incidence of congenital anomalies in antenatal mothers.

\begin{tabular}{|c|c|c|c|c|}
\hline S.NO & Systems & Incidence & $\begin{array}{l}\text { Congenital Anomalies } \\
\qquad(\mathrm{N}=265)\end{array}$ & $\begin{array}{c}\text { Total } \\
(\mathrm{N}=265)(\mathrm{n}=3.4 \%)\end{array}$ \\
\hline \multirow{4}{*}{1} & \multirow{4}{*}{ Renal } & \multirow{4}{*}{1.1} & B/L Hydronephrosis (>10 mm) (43) & \multirow{4}{*}{$83(31.4 \%)$} \\
\hline & & & PUV(28) & \\
\hline & & & Multicystic dysplastic kidney (9) & \\
\hline & & & Ectopic Kidney(3) & \\
\hline \multirow{5}{*}{2} & \multirow{5}{*}{ CVS } & \multirow{5}{*}{0.87} & Intracardiac Rhabdomyoma (34) & \multirow{5}{*}{$66(24.9 \%)$} \\
\hline & & & Congenital heart diseases (17) & \\
\hline & & & Pericardial effusion (8) & \\
\hline & & & Single umbilical artery (7) & \\
\hline & & & CTEV (27) & \\
\hline \multirow{4}{*}{3} & \multirow{4}{*}{ Musculoskeletal } & \multirow{4}{*}{0.52} & Syndactyl and polydactyl (12) & \multirow{4}{*}{$40(15.2 \%)$} \\
\hline & & & Sirenomelia (1) & \\
\hline & & & Hydrocephalus (17) & \\
\hline & & & Neural tube defects (15) & \\
\hline \multirow{4}{*}{4} & \multirow{4}{*}{ CNS } & \multirow{4}{*}{0.51} & $\begin{array}{l}\text { (Meningocele-6, Meningomyelocele-5, Spina } \\
\text { bifida-2, Anencephaly-2 ) }\end{array}$ & \multirow{4}{*}{$39(14.7 \%)$} \\
\hline & & & Choroid plexus cyst (5) & \\
\hline & & & Sacrococcygeal teratoma (2) & \\
\hline & & & TEF(9) & \\
\hline \multirow{4}{*}{5} & \multirow{4}{*}{ Respiratory } & \multirow{4}{*}{0.5} & $\mathrm{CDH}(8)$ & \multirow{4}{*}{$21(7.9 \%)$} \\
\hline & & & $\operatorname{CPAM}(4)$ & \\
\hline & & & Cleft Lip / Cleft Palate(4) & \\
\hline & & & Omphalocele(3) Gastroschisis(1) & \\
\hline
\end{tabular}




\begin{tabular}{|c|c|c|c|c|}
\hline \multirow{2}{*}{6} & \multirow{3}{*}{ GIT } & \multirow{2}{*}{0.13} & Duodenal atresia(2) & \multirow{2}{*}{$12(4.5 \%)$} \\
\cline { 3 - 3 } & & & Hypertrophic pyloric stenosis(1) & \\
\cline { 3 - 4 } & Genetics & 0.07 & Splenic cyst (1) & \multirow{2}{*}{$4(1.4 \%)$} \\
\hline
\end{tabular}

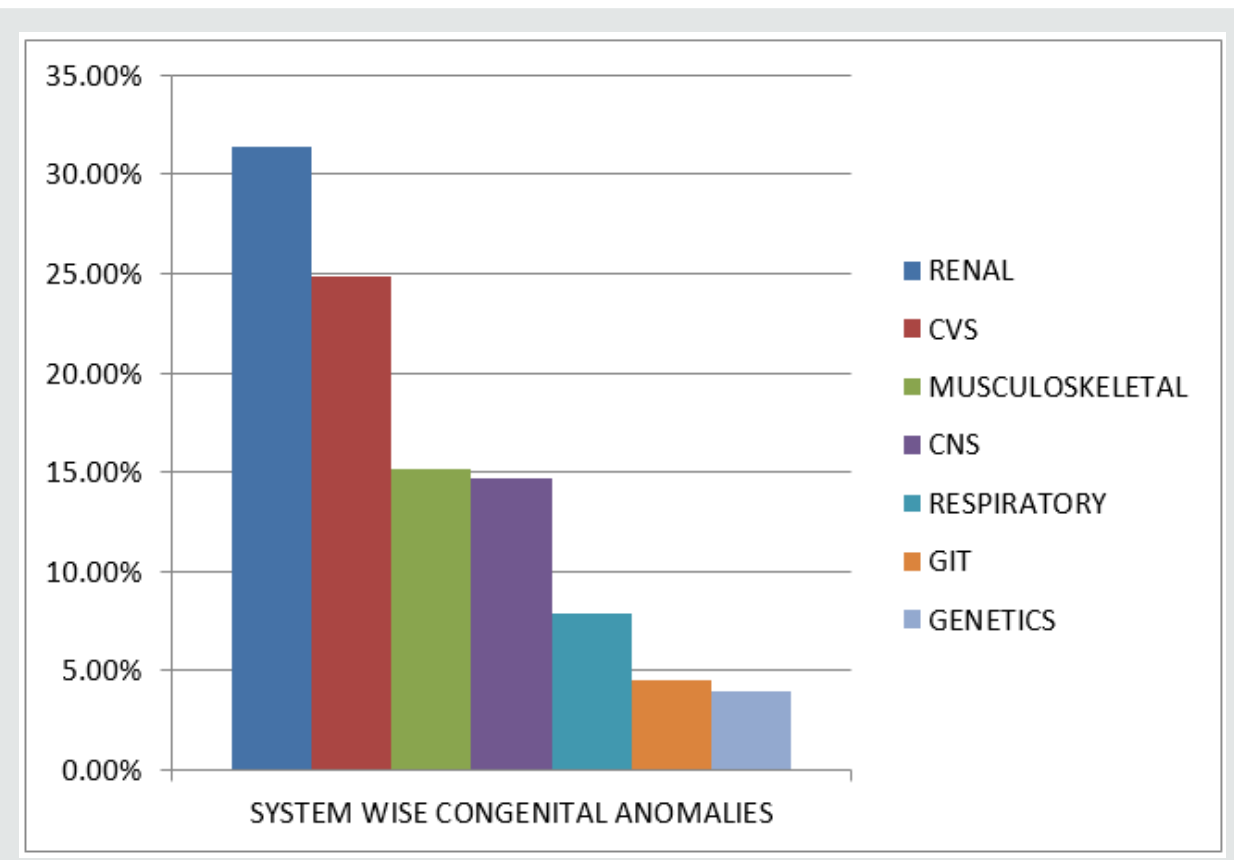

Figure 1: System Wise Incidence of Antenatal Congenital Anomalies.

\section{Discussion}

The diagnosis of major congenital anomalies has improved dramatically in the past few years and is mainly attributable to advancements in ultrasound systems technology. Increase in awareness of antenatal folic acid supplementation has significantly reduced the incidence of neural tube defects. The antenatal incidence of congenital anomalies in the present study was $3.4 \%$, which is comparable with the observations in Sallout et al. (2.96\%) [7] and Alia (2.97\%) [8]. On the contrary, Nakling [9], Souka [10], Taboo [11] and Alakananda et al. [12] showed lower incidence than the present study. The variation could be due to social factors, Ethnic factors, Nutritional status, and geographical areas. Risk factors associated with congenital anomalies are maternal age, consanguinity, perinatal environmental exposures, Prenatal folic acid deficiency, polyhydramnios, maternal radiation exposure and teratogenic drugs.
The present study shows elderly maternal age group (>30 years) and multipara have high risk for congenital anomalies as comparable with Singh A [13]. The higher incidence in our study compared to previous studies done in the Indian settings could be possibly explained due to the fact that the study was conducted in a tertiary care hospital which is a referral center for high risk pregnancies throughout the district. In present study, congenital anomalies of the Renal system was the highest (31.4\%) followed by anomalies of the Cardiovascular system (24.9\%), musculoskeletal(15.2\%), Central nervous system(14.7\%), Respiratory system(7.9\%), Gastro-intestinal tract(3.7\%) and Genetics(2.2\%). Among the renal system, Bilateral hydronephrosis was the most common defect of all isolated birth defects which constitutes around $16.22 \%$, which is $51.3 \%$ of neonates with renal defects. Among fetal abdominal defects, omphalocele (25\%) was 3 times more common than gastroschisis (8.33\%). (Figure 2). 


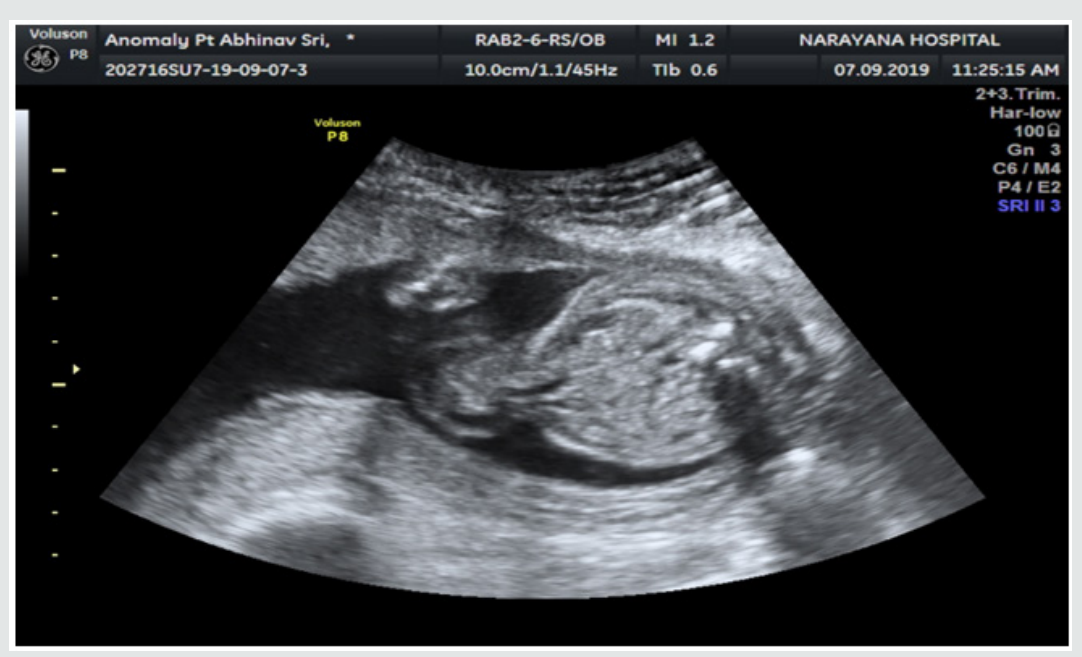

Figure 2: Antenatal Usg Showing Fetus with Omphalocele.

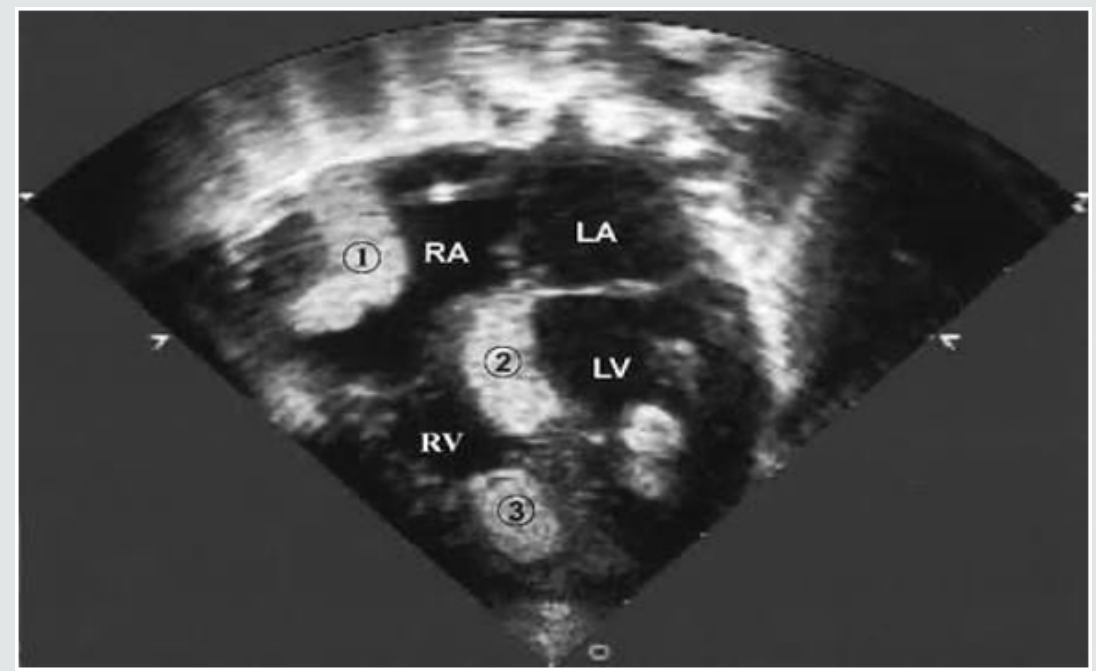

Figure 3: Antenatal Usg Showing Fetus with Intracardiac Rhabdomyoma.

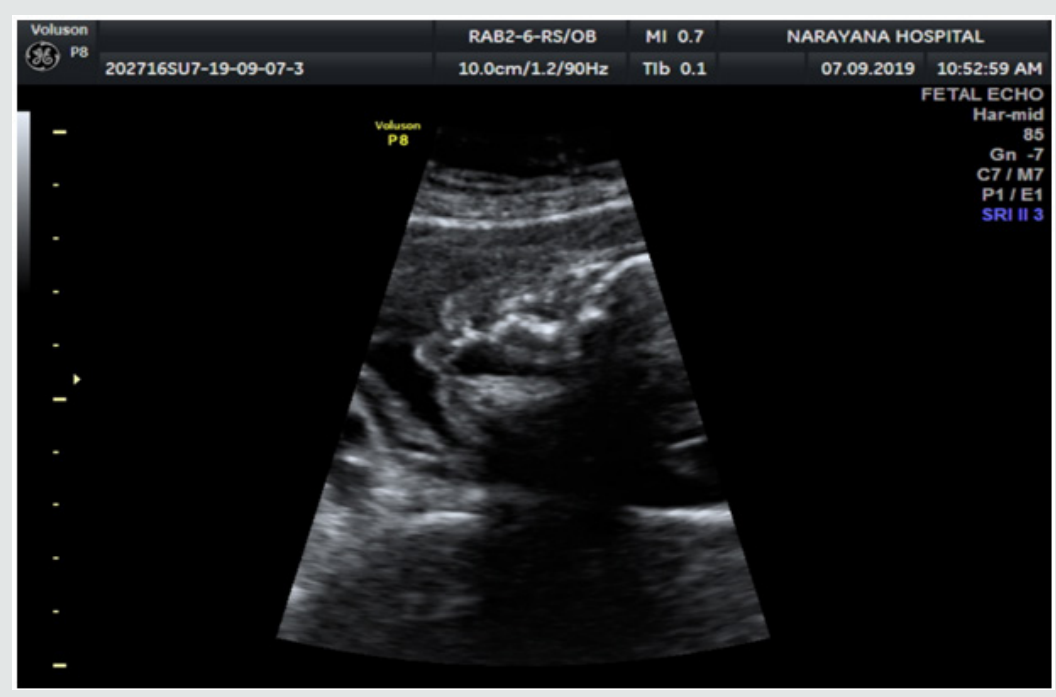

Figure 4: Antenatal Usg Showing Fetus with Cleft Palate. 
Congenital talipes equino varus (CTEV) was commonly associated with oligohydramnios and intra-uterine growth retarted (IUGR) fetus (Figure 5). In the present study, all those mothers who were diagnosed with congenital anomalies in the 2 nd \& 3 rd trimester TIFFA scans were counselled by Neonatologist about the various treatment options and the subsequent postnatal managements available for that particular anamaly. Antenatal ultrasound detection of congenital anomalies was followed by patient counselling, decision making for or against continuation of pregnancy, if diagnosed before 20 completed weeks and subsequent treatment options. Our study has highlighted that renal and cardiovascular anomalies as the commonest. Though antenatal screening is an effective tool to detect anomalies, few anomalies may be missed by routine anomaly scan. Hence, fetal echocardiogram and fetal MRI should be advised in high risk mothers.

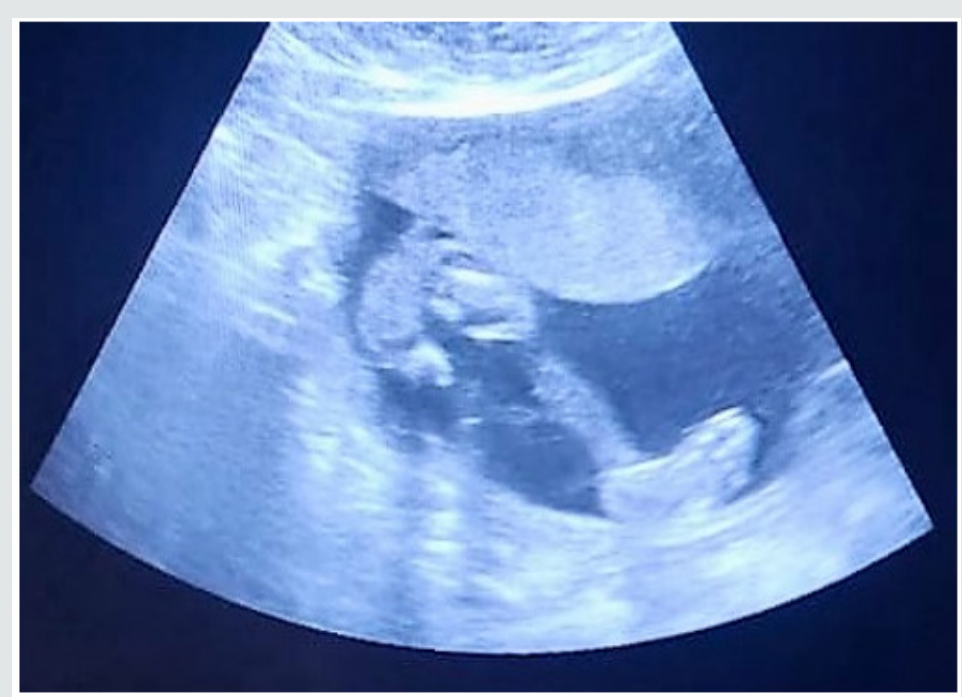

Figure 5: Antenatal Usg Showing Fetus with Ctev.

\section{Conclusion}

In this study incidence of fetal congenital anomaly was found to be $3.4 \%$. Renal defect was found to be the commonest form of anomaly in our study population. In this study we have demonstrated that the major contributing factors for congenital anomalies were consanguinity, multiparity and diabetes mellitus. Incidence of neural tube defects are much less in our study because of widespread knowledge about iron and folic acid supplements during perinatal period. Incidence of antenatally detected congenital anomalies has increased compared to the past because of advanced diagnostic facilities and better-trained radiologists in fetal medicine. The incidence of antenatally detected congenital anomalies are higher in our study due to high risk referrals from other hospitals for tertiary care management.

\section{Funding}

No funding sources.

\section{Conflict of Interest}

None.

\section{Ethical Approval}

The study was approved by the Institutional Ethics Committee.

\section{References}

1. WHO (2012) World Health Organization. Section on congenital anomalies.

2. National health Portal of India. Section on congenital anomalies (birth defects).

3. Carmona RH (2005) The global challenges of birth defects and disabilities. Lancet 366(9492): 1142-1144.

4. UNICEF. Neonatal Health. Available at Unicef.in/whatwedo/2/NeonatalHealth.

5. JAMA (2011) Causes of death among stillbirths. Stillbirth collaborative research network 306(22): 2459-2468.

6. Patel ZM, Adhia RA (2005) Birth defects surveillance study. Indian J Paediatr 72(6): 489-491.

7. Sallout BI, Al-Hashan MS, Attyyaa RA (2008) Antenatal diagnosis, prevalence and outcome of major congenital anomalies in Saudi Arabia: a hospital based study. Ann Saudi Med 28(4): 272-276.

8. Alia N, Ahmed I (2010) Congenital anomalies: prevalence of abnormalities in $2^{\text {nd }}$ trimester of pregnancy in Madina teaching hospital, Faisalabad on grey scale ultrasound JUMDC 1(1): 23-28.

9. Nakling J, Backe B (2005) Routine ultrasound screening and detection of congenital anomalies outside a university setting. Acta Obstetricia et Gynecologica Scandinavica 84(11): 1042-1048.

10. Souka AP, Pilalis A, Kavalakis I (2006) Screening for major structural abnormalities at the 11- to 14-week ultrasound scan. American Journal of Obstetrics and Gynecology 194(2): 393-396.

11. Taboo ZAA (2012) Prevalence and risk factors for congenital anomalies in Mosul city. The Iraqi Postgraduate Medical Journal 11(40): 458-470. 
12. Alakananda, Choudhury SS, Neiting C (2005) A study on prevalence of congenital anomalies of foetuses among pregnant women in a tertiary care hospital and its association with socio-demographic factors. The New Indian Journal of OBGYN 2(1): 4650.

13. Singh A. Ravinder K, Jammu S (2009) Pattern of Congenital Anomalies in Newborn: A Hospital Based Prospective, Jammu (J\&K)-India 11: 346.
14. Gokul Krishnan R, Nirmala P, Kamalarathnam CN (2020) Intracardiac rhabdomyoma in neonates-A case series: International journal of scientific research.

\section{CC (i) This work is licensed under Creative}

To Submit Your Article Click Here: Submit Article

DOI: $10.32474 /$ PAPN.2020.02.000144

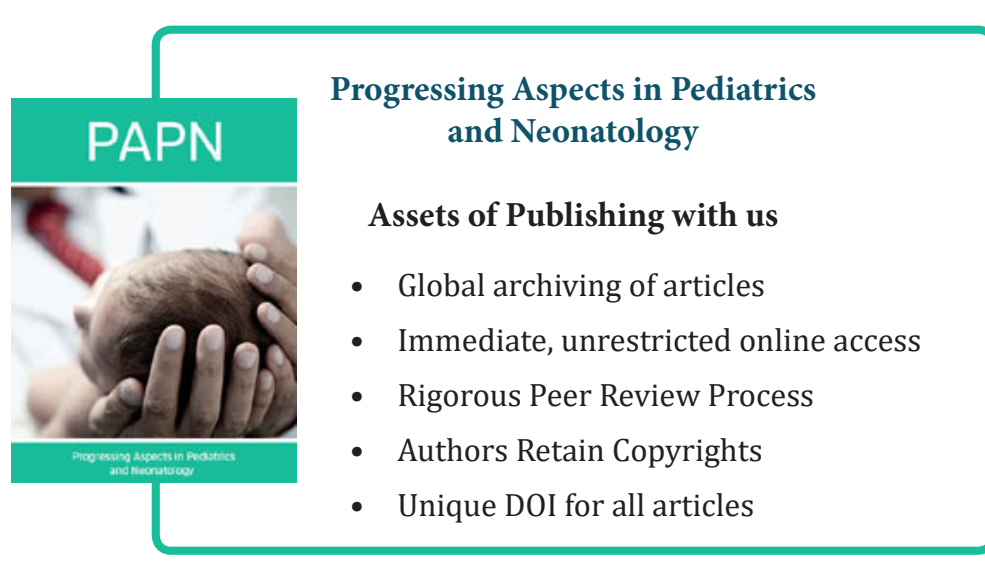

